Review

\title{
Advances in Risk Factors for Recurrence of Common Bile Duct Stones
}

\author{
Yao $\mathrm{Wu}^{1}$, Chen Jing $\mathrm{Xu}^{1}$, Shun $\mathrm{Fu} \mathrm{Xu}^{1,2^{凶}}$ \\ 1. Sir Run Run Hospital, Nanjing Medical University, Nanjing, 211100, China \\ 2. Jiangsu Province Hospital, Nanjing Medical University, Nanjing, 210029, China \\ $\square$ Corresponding author: Shun Fu Xu, Sir Run Run Hospital, Nanjing Medical University. Jiangsu Province Hospital, Nanjing Medical University. Nanjing, \\ China. Email: dr_water@163.com \\ (c) The author(s). This is an open access article distributed under the terms of the Creative Commons Attribution License (https://creativecommons.org/licenses/by/4.0/). \\ See http://ivyspring.com/terms for full terms and conditions.
}

Received: 2020.09.07; Accepted: 2020.12.22; Published: 2021.01.01

\begin{abstract}
Choledocholithiasis is a chronic common disease. The incidence of cholelithiasis is $5 \%-15 \%$, of which $5 \%-30 \%$ are combined with Choledocholithiasis. Although endoscopic cholangiopancreatography (ERCP) + endoscopic sphincterotomy (EST) is the most common treatment procedure, which clearance rate is up to $95 \%$, the incidence of recurrent choledocholithiasis was $4 \%-25 \%$. The risk factors of recurrence after choledocholithiasis clearance are the focuses of current researches, which are caused by multiple factors. We first systematically summarize the risk factors of common bile duct stones (CBDS) recurrence into five aspects: first-episode stone related factors, congenital factors, biological factors, behavioral intervention factors, and the numbers of stone recurrence.
\end{abstract}

Key words: common bile duct stones; ERCP; recurrence; risk factors

\section{Introduction}

Choledocholithiasis, one of the most common digestive diseases, is a chronic recurrent hepatobiliary disease whose pathological bases are impaired cholesterol, bilirubin, and bile acid metabolism. The incidence of cholelithiasis is $5 \%$ to $15 \%$, in which the incidence of Choledocholithiasis is about 5\%-30\%.(19, 71) Age, gender, genetic factors, factors related to metabolic syndrome, dietary factors , and drugs are all risk factors for Choledocholithiasis.(43) At present, endoscopic cholangiopancreatography (ERCP) + endoscopic sphincterotomy (EST) is the most common treatment procedure. ERCP intubation success rate is up to $98 \%$, the clearance rate is up to $95 \% .(25,55)$ However, a large number of follow-up observations showed that the recurrence rate of common bile duct stone after endoscopic treatment was $4 \%-25 \% .(60,65)$ Choledocholithiasis may cause acute suppurative cholangitis, pancreatitis, biliary perforation, etc. The recurrent factors of choledocholithiasis are complex and cannot be explained by a single factor. Therefore, this article reviews the recurrence factors of choledocholithiasis (Fig. 1).

There is no uniform standard for the definition of the recurrence time. It is commonly considered that the recurrence of choledocholithiasis is defined as 6 months after the complete resection of primary stones. $(39,45,77)$

\section{Related factors of first-episode common bile duct stones}

\section{Size and number of stones}

Feng Deng et al. (19) found that the diameter of choledocholithiasis $\geq 10 \mathrm{~mm}$ was an independent risk factor for the recurrence of choledocholithiasis after ERCP. The larger the stone diameter, the larger the bile duct dilatation. When the normal bile duct motor function is affected, cholestasis and bile duct bacterial infection are easy to be caused, which is conducive to the formation of bile pigment stones. At the same time, when the stones are too large to be removed, most of them need in vitro ultrasonic lithotripsy, which is also a reason for the recurrence of large stones. Eun Soo Yoo (96) believed that multiple choledocholithiasis $(\geq 2)$ was a related factor for the recurrence. However, Cheon suggested that the 
number and size of stones were the risks of residual bile duct stones after EST, rather than the risk of recurrence of bile duct stones.(29) Different outcomes may be related to the number of stones defined, the size of the diameter, and the treatment regimen taken.

\section{Composition and properties of stones}

The chemical composition of bile under the physiological state is balanced, and it is not easy to form stones. Sugiyama followed patients after EST for up to 10 years and found that recurrent stones were all brown pigment stones. Bacteria, cholestasis and papillary stricture may play an important role.(58) Muddy stones are more likely to remain in the common bile duct. Small stone fragments missed by cholangiography may be the cause of stone aggregation and recurrence.(6) However, YOO found that there was no significant correlation between muddy stones and common bile duct stones.(96) There may be limited data on the consistency of stone, such as whether it is muddy or hard.

\section{Stones' position}

The common bile duct is divided into four sections: the upper, posterior, pancreatic, and inner duodenal wall. The lower stones cause more bile retention, resulting in greater biliary wall pressure and greater degree of damage. Meanwhile, the closer the stone to the Oddi sphincter, the more damage it will have to its function. These may aggravate the recurrence of common bile duct stones. But there are no studies, and we are analyzing them.

\section{Congenital factors}

\section{Gender}

We all know that women are more likely to develop choledocholithiasis, which is associated with higher estrogen levels and less exercise. The decreased contractile force of the gallbladder muscles leads to delayed cholestasis and the precipitation of cholesterol crystals. However, most of the studies believed that there was no significant correlation between gender and the recurrence of common bile duct stones. $(39,80)$

\section{Age}

The recurrence rate of choledocholithiasis in patients over 65 years old is as high as 30\%.(26) Parra-membrives Pablo found that age was the only independent risk factor, with $86.4 \%$ occurring over 65 years of age.(66) Common bile duct (CBD) expansion, $\mathrm{CBD}$ angulation, and periampullary diverticulum (PAD) were all associated with the recurrence of calculi in elderly patients.(36)

\section{Metabolism}

Metabolic syndrome-related factors, such as abnormal lipid metabolism, hypercalcemia, hyperuricemia, obesity, lack of physical activity, insulin resistance, diabetes, and nonalcoholic fatty liver are risk factors for the occurrence of choledocholithiasis.(43) Since these related factors do not disappear after stone removal, we believe that they are also risk factors for the recurrence of choledocholithiasis.

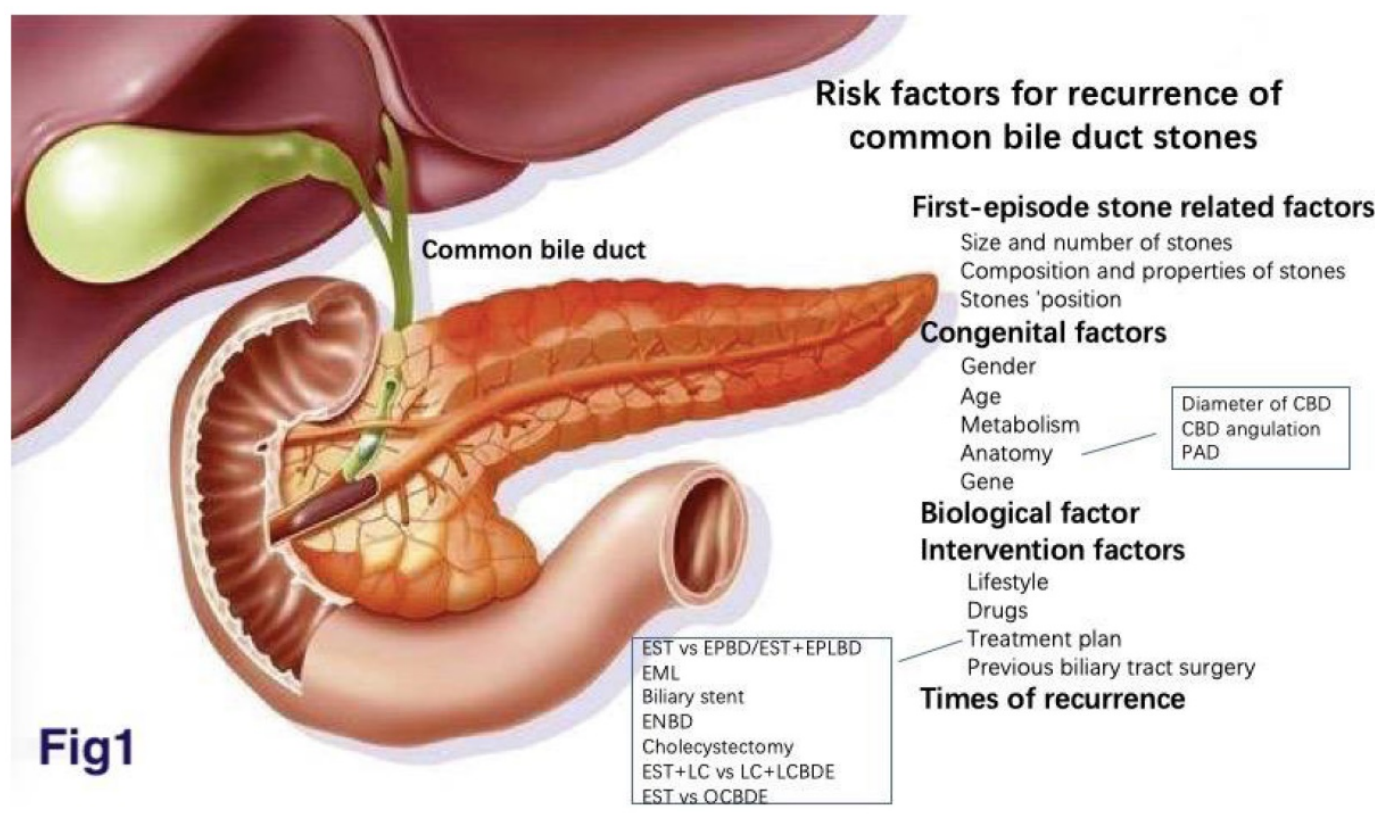

Figure 1. The recurrence factors of choledocholithiasis 


\section{Anatomy}

Diameter of common bile duct

Long-term dilatation of the common bile duct results in decreased retraction of the smooth muscle fibers, impaired function, and difficulty in bile excretion, which is easy to result in cholestasis and bacterial infection, and promote the formation of stones. (87) Patients with common bile duct diameter of $15 \mathrm{~mm}$ or larger were more likely to have a recurrence of symptoms and the risk of recurrence of stones was almost four times higher than those with a diameter of $10 \mathrm{~mm}$ or less.(67) Although it has been confirmed that the diameter of common bile duct is a risk factor for the recurrence, the specific diameter has not yet been determined. Deng (19) and Park (65) believed 10mm, but Song (77) and Yoo (96) believe that the diameter of common bile duct $\geq 15 \mathrm{~mm}$ is a potential predictor after endoscopic stoning. It is worth mentioning that Jeon Jin et al. (31) found that there is an inverse relationship between restoration of CBD diameter within two weeks and CBD stone recurrence.

\section{Common bile duct angulation}

The common bile duct usually leans to the right toward the duodenum during descent, which is called angulation. The bile flow speed is inversely proportional to the Angle of the bile duct. The prolonged biliary drainage time causes bile concentration, thus leading to the increase of cholesterol saturation, the decrease of bile duct systolic function, and a series of reactions such as unsaturated bile cannot be excluded, creating conditions for the recurrence of bile duct stones.(37) There is no consensus on relationship between the specific angle and the recurrence. Keizmam et al. (35) and Ryu Seongyul et al. (73)reported $\leq 145^{\circ}$, but Rongchun et al. believed $\leq 135^{\circ}$. (97) Chong et al. found $130^{\circ}$ was a special angle.(16) The difference in Angle may be related to preoperative/postoperative tablet reading, which requires further big data study. At the same time, the current data is based on the two-dimensional plane, which is not as accurate as the three-dimensional plane.

\section{Periampullary duodenal diverticulum (PAD)}

Most of the PAD is located within $2-3 \mathrm{~cm}$ of the duodenal nipple. PAD can be divided into three types: Type I: the nipple is located within the diverticulum; Type II: The nipple is located at the inner edge of the diverticulum; Type III: The nipple is located outside the diverticulum. (77) More than $75.5 \%$ of PAD cases occurred in patients older than 50 years. (54) PAD goes hand in hand with the formation of the stones $(52,74)$, but it is still unclear what is the mechanism of PAD causing the recurrence. The possible mechanism is as follows: (1) the inverse vertical overgrowth of bacteria and its spread to the biliary tract system; meanwhile, food was deposited in the diverticulum, forming a good medium for the bacteria. (2) The periampullary diverticulum may affect the normal anatomy of the nipple, causing compression of distal duct and expansion of the upper duct. (3) Patients with elevated biliary pressure or biliary spasm may cause the Impaired bile outflow.(76) The size and type of PAD are associated with diameter of CBD and recurrence of choledocholithiasis. Choledocholithiasis recurrence rates of PAD I type were higher than PAD II and III type.(79) The mean age and common bile duct diameter of patients with $\mathrm{PAD}<15 \mathrm{~mm}$ were lower than those with PAD size $\geq 15 \mathrm{~mm}$.(38)

\section{Gene}

A study of 43,141 Swedish twins with gallstone disease found that about 25 percent of the risk of gallstone disease was genetically determined.(33) Mutations in some genes may be responsible for the formation of gallstones. $(7,8,44)$ ABCB4 (encoding the hepatobiliary flippase) gene mutation has been confirmed to be the main genetic risk factor for gallstone recurrence.(72) The ABCB4 gene is involved in encoding multi-drug resistance protein 3 (MDR3) of the hepatcholine transporter, and MDR3 damage leads to reduced levels of phosphatidylcholine and promoting the formation of stony bile. The ABCG5/8 (encoding the hepatobiliary cholesterol transporter $5 / 8$ ) allele is interrelated with the recurrence of choledocholithiasis, and its variant gene ABCG D19H is currently recognized as a genetic risk factor for the formation of gallstones, which can effectively predict the recurrence of choledocholithiasis.(89)

\section{Biological factors}

Exogenous $\beta$-glucuronidase produced by anaerobes can hydrolyze bilirubin to unbound bilirubin (UCB) and glucuronic acid. Bacterial production of phospholipase A1 hydrolyzes lecithin (phosphatidylcholine) to produce free palmitic and stearic acids. The conjugated bile salts can be hydrolyzed by anaerobes' conjugated bile salt hydrolysates to form insoluble free bile acids. The above products can be combined with calcium ions in bile to form insoluble precipitation, which becomes the core framework of brown stones.(10, 56, 88, 90) The bacteriological and morphological studies of 38 brown stone specimens showed that the positive rate of bacterial culture was $80.5 \%$, and enterococcus was the most common microorganism isolated.(46) The 
inflammatory pathological changes of the bile duct epithelium can persist for a long time after the removal of bile duct stones. Therefore, we believe that preoperative biliary tract infection in patients with first-episode stones may affect the relapsing of common bile duct stones due to impaired biliary tract function.

Microbiota cause disease through dysbiosis and shift in local distribution. Chen et al.(12) analyzed the bacterial 16S rRNA sequence. LEfSe analysis was used to further determine that there was a significant difference in abundance between patients with recurrent choledocholithiasis and patients with new choledocholithiasis. Patients with recurrent choledocholithiasis were mainly Aeromonas, Enterococcus, Unclassified_Enterobacteriaceae, and Citrobacter. The authors are conducting this study from different levels, such as phylum, class, order, family, genus and species, and we speculate that the mechanism of microflora causing stone recurrence might be the change of dominant microflora, rather than the change of the entire biliary population. However, whether certain microflora changes in the recurrent group are associated with the recurrence of choledocholithiasis remains to be further studied.

In recent years, helicobacter pylori, $\mathrm{HBV}, \mathrm{HCV}$, Clonorchis sinensis, ascaris, and schistosomiasis have also been found to increase the risk of recurrence of choledocholithiasis. $(47,51)$

\section{Intervention factors}

\section{Lifestyle}

Some studies have shown that a typical diet high in calories, cholesterol, fatty acids, or carbohydrates increases the risk of gallstones. $(18,21,84)$ Physical activity reduces biliary cholesterol saturation by increasing HDL-C (23) and by affecting plasma TG and insulin release (82). But there is no study on the influence of systematic classified dietary factors or exercise on the recurrence of choledocholithiasis.

\section{Drugs}

UDCA (Ursodeoxycholic acid) may effectively prevent the recurrence of choledocholithiasis by promoting the dissolution of cholesterol stones and reducing cholestasis. $(78,91)$ UDCA has a protective effect on recurrence after choledocholithiasis resection. $(13,93)$ However, some cases have been reported that UDCA promotes stone recurrence, but the mechanism remains unknown. The occurrence of biliary and duodenal anastomosis and recurrent biliary tract infection is associated with the formation of UDCA stones.(2) PPI (Proton pump inhibitor) is found as a hazard factor for choledocholithiasis relapsing after EST. The possible mechanism is that
PPI may increase the risk of choledocholithiasis recurrence by promoting the overgrowth of bacteria in the small intestine and changing the bacterial mixture in bile.(28)

\section{Treatment plan}

Nowadays, the treatment of patients with choledocholithiasis is relatively mature, and minimally invasive endoscopic treatment is the mainstream strategy. Some of the less widely used strategies include laparoscopic common bile duct exploration (LCBDE), open common bile duct exploration (OCBDE), dissolution, extracorporeal shock wave lithotripsy (ESWL), percutaneous radiation, electrohydraulic lithotripsy (EHL), and laser lithotripsy.(4, 48, 57, 61, 62, 69)

\section{EST vs EPBD /EST+EPLBD}

EST was applied in the treatment of choledocholithiasis in 1974, initiating a new era in the treatment. Actually, a study from 11 centers showed that EST was a risk factor for recurrence.(95)The possible reasons for the recurrence of choledocholithiasis after EST include bile duct inflammation, papillary stricture, choledochal dilatation, diverticulum, duodenal contents returning to the bile duct, foreign body in the bile duct, etc. EPBD is an alternative therapy for choledocholithiasis. $(81,85)$ EPBD can retain 70\% ODDI sphincter function, and has fewer biliary complications, improve long-term prognosis, and lower stone recurrence rate. $(22,41)$ However, EPBD is not widely used because of its association with a higher incidence of pancreatitis and the use of mechanical lithotripsy. $(50,83)$ Compared with simple EST, small incision EST combined with EPBD showed close success rate of treatment of common bile duct stones, but the recurrence rate of postoperative stones was significantly reduced and the need for lithotripsy was greatly reduced. (53)The smallest duodenal papillary incision could prevent the recurrence of choledocholithiasis.(59) However, some studies showed that the recurrence rate of common bile duct stones after EST combined with large balloon dilatation of the nipple under endoscope corresponds to that of the simple EST or EPLBD.(40) (14) This difference may be related to the size of the nipple incision and bile duct dilation.(42) Kim (40) believed that the diameter of common bile duct $\geq 22 \mathrm{~mm}$ was a risk factor, which needed more research and verification.

\section{Mechanical lithotripsy under endoscope (EML)}

For the bile duct is difficult to clear the huge stone, to be taken out after lithotripsy. EML may lead to residual small stone fragments in the common bile duct, which cannot be detected by cholangiography. 
These micro-stones form the core of the stone again, which becomes a hidden risk for the recurrence of choledocholithiasis. Lithotripsy was an independent risk factor for the recurrence of choledocholithiasis. If the stones were not removed completely during lithotripsy, a stent was used to drain enough cholestasis to reduce the recurrence of stones.(49)

\section{Biliary stent}

Biliary stenting is considered as an alternative choice to EST in the elderly.(1, 5, 17) Ueda et al. treated 66 patients with acute obstructive cholangitis due to CBDS by biliary stent implantation, but not EST. They found that short-term stenting without EST eliminated choledocholithiasis while the duodenal papillary function is preserved.(86) What's more, Choi Jung-Hye found that stenting for A short period (one month when liver function normalized) after ERCP can reduce the risk of stone recurrence.(15) However, Kaneko et al.(32) found that long-term ( $\geq 301$ days) placement of plastic stents and bile duct dilation during stent implantation were independent factors for SSC (stent-stone complex) formation. Short-term use of biliary stents can fully drain bile and relieve cholestasis, reducing small residual stones, which can reduce the risk of common bile duct stone recurrence. However, long-term implantation can induce bacterial proliferation and promote the occurrence of stones.

\section{Endoscopic nasobiliary drainage (ENBD) and saline preventive irrigation}

ENBD after ERCP can reduce the recurrence rate of stones. Nasobiliary drainage can increase positive biliary pressure to promote biliary drainage and reduce biliary reflux. The pre-existing cholestasis and biliary inflammation can be cleared to a certain extent(94), thus reducing the incidence of choledocholithiasis. Meanwhile, for multiple small stones that are difficult to remove, nasobiliary drainage helps to reduce residual stones. Alternatively, prophylactic saline irrigation of the biliary tract after ERCP may also reduce the recurrence of common bile duct stones. $(24,30)$

\section{Cholecystectomy}

Cholecystectomy after ERCP is still a controversial topic. The2017 UK guidelines for the treatment of choledocholithiasis stated that: All the cholecystolithiasis or patients with gallstones should undergo cholecystectomy unless there are specific cases where surgery is not permitted.(92) But in practice, it's not that simple.(27) Partial recurrence of choledocholithiasis may result from gallbladder metastasis. Therefore, prophylactic cholecystectomy after ERCP treatment of choledocholithiasis could reduce recurrence.(34) However, the gallbladder can excrete bile and flush the biliary tract to prevent the stones formation. This function is also lost when the gallbladder is removed. Park et al.(65) showed a prior history of cholecystectomy can increase the risk recurrence of choledocholithiasis after LCBDE and reported that prophylactic cholecystectomy was not required to prevent recurrence of choledocholithiasis in Asian populations without stones after ERCP stone removal. YOO et al.(96) found that cholesterol stones were a risk factor for the recurrence of choledocholithiasis after cholecystectomy. Accordingly, the diagnosis of primary or secondary choledocholithiasis is very important.

It's suggested that cholecystectomy should be considered carefully in elderly patients, as they have low relative risks of recurrence of stones and may have high surgical complications. (64) However, CBD expansion resulting from cholecystectomy in youth is another acquired risk factor for CBDS.(9) Besides, early (usually one week) cholecystectomy after EST in patients with choledocholithiasis combined with gallbladder stones can prevent recurrent biliary complications.(70, 75)

\section{EST vs LCBDE}

Platt et al. reported that LCBDE had a higher clearance rate of choledocholithiasis than ERCP (96.7\% and 90\%, respectively).(68) Some retrospective comparative analyses and meta-analyses showed that the rate of recurrence was lower in the LCBDE group compared to the patients who had an EST. $(3,63)$ LC+LCBDE preserve the complete sphincter function of Oddi, which may be associated with the reduction of the recurrence rate of common bile duct stones. A larger sample size should be studied to clarify this conclusion.

\section{EST vs OCBDE}

Some clinicians believe that the recurrence rate of choledocholithiasis is higher after EST than after choledochotomy OCT. This may be associated with the occurrence of pancreatitis. However, there is little data on whether there is a difference between the two methods in the treatment of CBDS. Zhou et al.(98) concluded that compared with OCT, EST was superior to OCT in terms of duration of relief of biliary obstruction, duration of anesthesia, duration of surgery, and hospitalization days. However, there was no significant difference between OCT and EST in the recurrence and mortality of choledocholithiasis. This result needs to be further verified because most critical and elderly patients prefer to choose minimally invasive EST. Therefore, larger sample studies are needed. 


\section{Previous biliary tract surgery}

Previous biliary surgery (such as bile duct exploration and $\mathrm{T}$ tube drainage) can damage the bile duct wall and form scars, resulting in biliary stricture and poor bile excretion. At the same time, adhesion causes bile duct tilt, and bile angulation affects bile flow, which promotes the recurrence of stones. Multiple ERCP operations also aggravate Oddi sphincter injury and increase the chance of retrograde infection. $(20,49)$

\section{Times of recurrence}

Park et al. (64) conducted an average follow-up of 4.2 years among 46,181 south Korean patients with endoscopic choledocholithiasis, and found 5228 patients $(11.3 \%)$ with first-time recurrence of choledocholithiasis. The recurrence rate was low for the first time, high for the second and third time, 23.4 $\%$ and $33.4 \%$, respectively. It can be seen that the recurrence rate is directly proportional to the number of recurrence. Deng et al. conducted a follow-up study on 477 patients with recurrent choledocholithiasis and found that the recurrence rate was as high as $19.5 \%$ for the second recurrence and $44.07 \%$ for the third or more recurrence.(19) The possible reason is that multiple surgical treatments aggravate the injury of Oddi sphincter and induce the necrosis of bile duct epithelial cells, forming scars and leading to bile duct stricture. Local adhesions, resulting in bile duct angulation and cholestasis, lead to stone recurrence. Surprisingly, when Chang JH et al. (11) followed up 481 cases, they found that choledocholithiasis increased in the recurrence period, $10.1 \pm 5.2 \mathrm{~mm}$ at the initial onset, $13.5 \pm 7.3 \mathrm{~mm}$ at the first recurrence, and $16.8 \pm 7.8 \mathrm{~mm}$ at the second recurrence. Therefore, regular follow-up examination is suggested for those who have had a recurrence, and it is recommended to follow up once every 1-2 years.

\section{Competing Interests}

The authors have declared that no competing interest exists.

\section{References}

1. Akazawa Yu. OM, Nosaka Takuto., Saito Yasushi., Takahashi Kazuto., Naito Tatsushi., Ofuji Kazuya., Matsuda Hidetaka., Hiramatsu Katsushi., Nemoto Tomoyuki., Nakamoto Yasunari. Long-term prognosis after biliary stenting for common bile duct stones in high-risk elderly patients. J Dig Dis. 2018;19:626-34.

2. Akiyama S, Imamura T, Tamura T, Koizumi Y, Koyama R, Takeuchi K, et al. Recurrent Common Bile Duct Stones Composed of Ursodeoxycholic Acid: A Report of Four Cases. Internal Medicine. 2014;53(21):2489-92.

3. Al-Habbal Y. RI, Tiang T., Houli N., Lai B., McQuillan T., Bird D., Yong T. Retrospective comparative analysis of choledochoscopic bile duct exploration versus ERCP for bile duct stones. Sci Rep. 2020;10:14736.

4. Baron TH, Harewood GC. Endoscopic Balloon Dilation of the Biliary Sphincter Compared to Endoscopic Biliary Sphincterotomy for Removal of Common Bile Duct Stones During ERCP: A Metaanalysis of Randomized, Controlled Trials. The American journal of gastroenterology. 2004;99(8):1455-60.
5. Bergman JJ RE, Tijssen JG, et al. . Biliary endoprostheses in elderly patients with endoscopically irretrievable common bile duct stones: report on 117 patients. Gastrointest Endosc. 1995;42:195-201.

6. Bove A, Bongarzoni G, Palone G, Di Renzo RM, Calisesi EM, Corradetti L, et al. Why is there recurrence after transcystic laparoscopic bile duct clearance? Risk factor analysis. Surgical Endoscopy. 2009;23(7):1470-5.

7. Buch S, Schafmayer C, Völzke H, Becker C, Franke A, von Eller-Eberstein H, et al. A genome-wide association scan identifies the hepatic cholesterol transporter ABCG8 as a susceptibility factor for human gallstone disease. Nature Genetics. 2007;39(8):995-9.

8. Buch Sea. Loci from a genome-wide analysis of bilirubin levels are associated with gallstone risk and composition. Gastroenterology. 2010;139:1942-51.

9. Caddy G R. KJ, Kirk S J., Allen M J., Moorehead R J., Tham T C. Natural history of asymptomatic bile duct stones at time of cholecystectomy. Ulster Med J. 2005;74:108-12.

10. CETTA F. The Role of Bacteria in Pigment Gallstone Disease. Annals of Surgery. 1991;213:315-26.

11. Chang Jae Hyuck. KTH, Kim Chang Whan., Lee In Seok., Han Sok Won. Size of recurrent symptomatic common bile duct stones and factors related to recurrence. The Turkish journal of gastroenterology : the official journal of Turkish Society of Gastroenterology. 2014;25:518-23.

12. Chen B, Fu SW, Lu L, Zhao H. A Preliminary Study of Biliary Microbiota in Patients with Bile Duct Stones or Distal Cholangiocarcinoma. Biomed Res Int. 2019;2019:1092563.

13. Chen $X$, Yan XR, Zhang LP. Ursodeoxycholic acid after common bile duct stones removal for prevention of recurrence. Medicine. 2018;97(45).

14. Cheon Young Koog. LTY, Kim Soo-Nyung., Shim Chan Sup. Impact of endoscopic papillary large-balloon dilation on sphincter of Oddi function: a prospective randomized study. Gastrointest Endosc. 2017;85:782-90.

15. Choi JH, Lee TY, Cheon YK. Effect of stent placement on stone recurrence and post-procedural cholangitis after endoscopic removal of common bile duct stones. Korean J Intern Med. 2020 Aug 24

16. Chong C, Chiu P, Tan T, Teoh A, Lee K, Ng E, et al. Correlation of CBD/CHD angulation with recurrent cholangitis in patients treated with ERCP. Endoscopy International Open. 2016;04(01):E62-E7.

17. Chopra KB, Peters RA, O'Toole PA, Williams SGJ, Gimson AES, Lombard MG, et al. Randomised study of endoscopic biliary endoprosthesis versus duct clearance for bileduct stones in high-risk patients. The Lancet. 1996;348(9030):791-3

18. Cuevas A, Miquel JF, Reyes MS, Zanlungo S, Nervi F. Diet as a Risk Factor for Cholesterol Gallstone Disease. Journal of the American College of Nutrition. 2004;23(3):187-96.

19. Deng F, Zhou M, Liu P-P, Hong J-B, Li G-H, Zhou X-J, et al. Causes associated with recurrent choledocholithiasis following therapeutic endoscopic retrograde cholangiopancreatography: A large sample sized retrospective study. World Journal of Clinical Cases. 2019;7(9):1028-37.

20. Deng Feng. ZM, Liu Ping-Ping., Hong Jun-Bo., Li Guo-Hua., Zhou Xiao-Jiang., Chen You-Xiang. Causes associated with recurrent choledocholithiasis following therapeutic endoscopic retrograde cholangiopancreatography: A large sample sized retrospective study World J Clin Cases. 2019;7:1028-37.

21. Di Ciaula Agostino. GG, Frühbeck Gema., De Angelis Maria., de Bari Ornella., Wang David Q-H., Lammert Frank., Portincasa Piero. The Role of Diet in the Pathogenesis of Cholesterol Gallstones. Curr Med Chem. 2019;26:3620-38.

22. Doi S, Yasuda I, Mukai T, Iwashita T, Uemura S, Yamauchi T, et al. Comparison of long-term outcomes after endoscopic sphincterotomy versus endoscopic papillary balloon dilation: a propensity score-based cohort analysis. J Gastroenterol. 2013 Sep;48(9):1090-6.

23. Dubrac S. PM, Blouquit $Y$, Gripois D, Blouquit M F, Souidi M, Lutton C. Insulin injections enhance cholesterol gallstone incidence by changing the biliary cholesterol saturation index and apo A-I concentration in hamsters fed a lithogenic diet. J Hepatol. 2001;35:550-7.

24. Endo R, Satoh A, Tanaka Y, Shimoda F, Suzuki K, Takahashi K, et al. Saline Solution Irrigation of the Bile Duct after Stone Removal Reduces the Recurrence of Common Bile Duct Stones. Tohoku J Exp Med. 2020 Mar;250(3):173-9.

25. Frey CF BE, Meinke WB, et al. . Endoscopic retrograde cholangiopancreatography. Am J Surg. 1982;144:109-14.

26. Fritz E, Kirchgatterer A, Hubner D, Aschl G, Hinterreiter M, Stadler B, et al. ERCP is safe and effective in patients 80 years of age and older compared with younger patients. Gastrointestinal endoscopy. 2006;64(6):899-905.

27. Fujimori Nao IH, Asou Akira et al. . Endoscopic approach through the minor papilla for the management of pancreatic diseases. World J Gastrointest Endosc. 2013;5:81-8.

28. Fukuba Nobuhiko IS, Sonoyama Hiroki et al. . Proton pump inhibitor is a risk factor for recurrence of common bile duct stones after endoscopic sphincterotomy-propensity score matching analysis. Endosc Int Open. 2017;5:E291-E6.

29. G CYL. Identification of risk factors for stone recurrence after endoscopic treatment of bile duct stones. Eur J Gastroenterol Hepatol. 2006;18:461-4.

30. Jang SE, Ahn D-W, Lee SH, Lee BS, Jeong JB, Hwang J-H, et al. Preventive Saline Irrigation of the Bile Duct After the Endoscopic Removal of Common Bile Duct Stones. Digestive diseases and sciences. 2013;58(8):2353-60.

31. Jeon Jin. LSU, Park Chang-Hwan., Jun Chung-Hwan., Park Seon-Young., Rew Jong-Sun. Restoration of common bile duct diameter within 2 weeks after 
endoscopic stone retraction is a preventive factor for stone recurrence. Hepatobiliary Pancreat Dis Int. 2018;17:251-6.

32. Kaneko J KK, Watanabe S, et al. Clinical characteristics and risk factors for stent-stone complex formation following biliary plastic stent placement in patients with common bile duct stones. Hepatobiliary Pancreat Sci. 2018;25:448-54.

33. Katsika D, Grjibovski A, Einarsson C, Lammert F, Lichtenstein P, Marschall $\mathrm{HU}$. Genetic and environmental influences on symptomatic gallstone disease: a Swedish study of 43,141 twin pairs. Hepatology. 2005 May;41(5):1138-43.

34. Kawaji Y, Isayama H, Nakai Y, Saito K, Sato T, Hakuta R, et al. Multiple recurrences after endoscopic removal of common bile duct stones: A retrospective analysis of 976 cases. J Gastroenterol Hepatol. 2019 Aug;34(8):1460-6.

35. Keizman D, Shalom MI, Konikoff FM. An angulated common bile duct predisposes to recurrent symptomatic bile duct stones after endoscopic stone extraction. Surgical Endoscopy. 2006;20(10):1594-9.

36. Keizman D, Shalom MI, Konikoff FM. Recurrent symptomatic common bile duct stones after endoscopic stone extraction in elderly patients. Gastrointestinal endoscopy. 2006;64(1):60-5.

37. Keizman D. SMI, Konikoff F M. An angulated common bile duct predisposes to recurrent symptomatic bile duct stones after endoscopic stone extraction. Surg Endosc. 2006;20:1594-9.

38. Kim CW, Chang JH, Kim JH, Kim TH, Lee IS, Han SW. Size and type of periampullary duodenal diverticula are associated with bile duct diameter and recurrence of bile duct stones. Journal of gastroenterology and hepatology. 2013;28(5):893-8.

39. Kim DI, Kim MH, Lee SK, Seo DW, Choi WB, Lee SS, et al. Risk factors for recurrence of primary bile duct stones after endoscopic biliary sphincterotomy. Gastrointest Endosc. 2001 Jul;54(1):42-8.

40. Kim Kook Hyun. RJH, Kim Tae Nyeun. Recurrence of bile duct stones after endoscopic papillary large balloon dilation combined with limited sphincterotomy: long-term follow-up study Gut Liver. 2012;6:107-12.

41. Kojima Y, Nakagawa H, Miyata A, Hirai T, Ohyama I, Okada A, et al. Long-Term Prognosis of Bile Duct Stones: Endoscopic Papillary Balloon Dilatation Versus Endoscopic Sphincterotomy. Digestive Endoscopy. 2010;22(1):21-4.

42. Kuo CM, Chiu YC, Liang CM, Wu CK, Lu LS, Tai WC, et al. The efficacy of limited endoscopic sphincterotomy plus endoscopic papillary large balloon dilation for removal of large bile duct stones. BMC Gastroenterol. 2019 Jun 18;19(1):93.

43. Lammert F, Gurusamy K, Ko CW, Miquel JF, Mendez-Sanchez N, Portincasa P, et al. Gallstones. Nat Rev Dis Primers. 2016 Apr 28;2:16024.

44. Lammert F, Sauerbruch T. Mechanisms of Disease: the genetic epidemiology of gallbladder stones. Nature Clinical Practice Gastroenterology \& Hepatology. 2005;2(9):423-33.

45. Lehman YKCaGA. Identification of risk factors for stone recurrence after endoscopic treatment of bile duct stones. European journal of gastroenterology \& hepatology. 2006;18:461-4.

46. Leung J W. SJY, Costerton J W. Bacteriological and electron microscopy examination of brown pigment stones. J Clin Microbiol. 1989;27:915-21.

47. Leung J W. YAS. Hepatolithiasis and biliary parasites. Baillieres Clin Gastroenterol. 1997;11:681-706.

48. Li KY, Shi CX, Tang KL, Huang JZ, Zhang DL. Advantages of laparoscopic common bile duct exploration in common bile duct stones. Wien Klin Wochenschr. 2018 Feb;130(3-4):100-4.

49. Li S, Su B, Chen P, Hao J. Risk factors for recurrence of common bile duct stones after endoscopic biliary sphincterotomy. J Int Med Res. 2018 Jul;46(7):2595-605.

50. Li T, Wen J, Bie L, Gong B. Comparison of the Long-Term Outcomes of Endoscopic Papillary Large Balloon Dilation Alone versus Endoscopic Sphincterotomy for Removal of Bile Duct Stones. Gastroenterology Research and Practice. 2018;2018:1-8.

51. Li X, Gao P. Hepatitis C Virus Infection Increases Risk of Gallstone Disease in Elderly Chinese Patients with Chronic Liver Disease. Scientific Reports. 2018;8(1)

52. Li X, Zhu K, Zhang L, Meng W, Zhou W, Zhu X, et al. Periampullary Diverticulum May Be an Important Factor for the Occurrence and Recurrence of Bile Duct Stones. World Journal of Surgery. 2012;36(11):2666-9.

53. Liu Pan. LH, Chen Yuanyuan., Wu Yu-Shen., Tang Maocai., Lai Liang. Comparison of endoscopic papillary large balloon dilation with and without a prior endoscopic sphincterotomy for the treatment of patients with large and/or multiple common bile duct stones: a systematic review and meta-analysis. Ther Clin Risk Manag. 2019;15:91-101.

54. Lobo DN BT, Iftikhar SY et al. Periampullary diverticula and pancreaticobiliary disease. Br J Surg 86:588-597. Br J Surg 1999:86:588-97.

55. Lyu Y, Cheng Y, Wang B, Zhao S, Chen L. Comparison of the Efficacy and Safety of Three Endoscopic Methods to Manage Large Common Bile Duct Stones: A Systematic Review and Network Meta-Analysis. J Laparoendosc Adv Surg Tech A. 2020 Aug 5.

56. MAKI T. Pathogenesis of Calcium Bilirubinate Gallstone. Annals of Surgery. 1966;164:90-100.

57. Manes G, Paspatis G, Aabakken L, Anderloni A, Arvanitakis M, Ah-Soune P, et al. Endoscopic management of common bile duct stones: European Society of Gastrointestinal Endoscopy (ESGE) guideline. Endoscopy. 2019 May;51(5):472-91.
58. Masanori Sugiyama MD, and Yutaka Atomi, M.D. Risk Factors Predictive of Late Complications After Endoscopic Sphincterotomy for Bile Duct Stones: Long-Term (More Than 10 Years) Follow-up Study. Am Coll of Gastroenterology. 2002;97:2763-7.

59. Mu H, Gao J, Kong Q, Jiang K, Wang C, Wang A, et al. Prognostic Factors and Postoperative Recurrence of Calculus Following Small-Incision Sphincterotomy with Papillary Balloon Dilation for the Treatment of Intractable Choledocholithiasis: A 72-Month Follow-Up Study. Digestive diseases and sciences. 2015;60(7):2144-9.

60. Nzenza TC, Al-Habbal Y, Guerra GR, Manolas S, Yong T, McQuillan T. Recurrent common bile duct stones as a late complication of endoscopic sphincterotomy. BMC Gastroenterol. 2018 Mar 15;18(1):39.

61. P Vlavianos KC, S Mandalia, M Anderson, J Thompson, D Westaby. Endoscopic balloon dilatation versus endoscopic sphincterotomy for the removal of bile duct stones: a prospective randomised trial. Gut. 2003;52:1165-9.

62. Paik KY, Kim EK. Laparoscopic Common Bile Duct Exploration After Unsuccessful Endoscopic Stone Removal. Journal of Laparoendoscopic \& Advanced Surgical Techniques. 2013;23(2):137-40.

63. Pan Long. CM, Ji Lin., Zheng Longbo., Yan Peijian., Fang Jing., Zhang Bin., Cai Xiujun. The Safety and Efficacy of Laparoscopic Common Bile Duct Exploration Combined with Cholecystectomy for the Management of Cholecysto-choledocholithiasis: An Up-to-date Meta-analysis. Ann Surg. 2018;268:247-53.

64. Park BK, Seo JH, Jeon HH, Choi JW, Won SY, Cho YS, et al. A nationwide population-based study of common bile duct stone recurrence after endoscopic stone removal in Korea. Journal of gastroenterology. 2017;53(5):670-8.

65. Park SY, Hong TH, Lee SK, Park IY, Kim TH, Kim SG. Recurrence of common bile duct stones following laparoscopic common bile duct exploration: a multicenter study. Journal of Hepato-Biliary-Pancreatic Sciences. 2019;26(12):578-82

66. Parra-Membrives Pablo. M-BD, Lorente-Herce José Manuel., Jiménez-Riera Granada., Sánchez-Gálvez María Ángeles. Choledocholithiasis recurrence following laparoscopic common bile duct exploration. Cir Esp. 2019;97:336-42.

67. Pereira-Lima JC JR, Winter UH, et al. Long-term results (7 to 10 years) of endoscopic papillotomy for choledocholithia- sis. Multivariate analysis of prognostic factors for the recurrence of biliary symptoms. . Gastrointest Endosc. 1998;48:457-64

68. Platt TE, Smith K, Sinha S, Nixon M, Srinivas G, Johnson N, et al. Laparoscopic common bile duct exploration; a preferential pathway for elderly patients. Annals of Medicine and Surgery. 2018;30:13-7.

69. POWELL KDVAPH. Exploration of the common bile duct: a comparative study. Br J Surg. 1979;66:389-91.

70. Reinders JSK, Goud A, Timmer R, Kruyt PM, Witteman BJM, Smakman N, et al. Early Laparoscopic Cholecystectomy Improves Outcomes After Endoscopic Sphincterotomy for Choledochocystolithiasis. Gastroenterology. 2010;138(7):2315-20.

71. Reshetnyak VI. Concept of the pathogenesis and treatment of cholelithiasis. World J Hepatol. 2012 Feb 27;4(2):18-34.

72. Rosmorduc O HB, Boelle PY, et al. ABCB4 gene mutationassociated cholelithiasis in adults. Gastroenterology. 2003;125:452-9.

73. Ryu Seongyul. JIH, Kim Seonhoo., Kim Yeon-Ji., Chung Woo Chul. Clinical Impact of Common Bile Duct Angulation on the Recurrence of Common Bile Duct Stone: A Meta-analysis and Review. Korean J Gastroenterol. 2020;76:199-205.

74. Sakamoto N, Kato S, Chinen K, Shinoura S, Kikuchi K. Predictors for bile duct stone recurrence after endoscopic extraction for naïve major duodenal papilla: A cohort study. Plos One. 2017;12(7)

75. Schiphorst AHW, Besselink MGH, Boerma D, Timmer R, Wiezer MJ, van Erpecum KJ, et al. Timing of cholecystectomy after endoscopic sphincterotomy for common bile duct stones. Surgical Endoscopy. 2008;22(9):2046-50.

76. Skar V SA, Osnes M. The duodenal bacterial flora in the region of papilla of Vater in patients with and without duodenal diverticula. Scand J Gastroenterol 1989;24:649-56.

77. Song ME, Chung MJ, Lee DJ, Oh TG, Park JY, Bang S, et al. Cholecystectomy for Prevention of Recurrence after Endoscopic Clearance of Bile Duct Stones in Korea. Yonsei Med J. 2016 Jan;57(1):132-7.

78. Stokes CS, Gluud LL, Casper M, Lammert F. Ursodeoxycholic acid and diets higher in fat prevent gallbladder stones during weight loss: a meta-analysis of randomized controlled trials. Clin Gastroenterol Hepatol. 2014 Jul;12(7):1090-100 e2; quiz e61.

79. Sun Zhen. BW, Jiang Ping., Sun Quan. Different Types of Periampullary Duodenal Diverticula Are Associated with Occurrence and Recurrence of Bile Duct Stones: A Case-Control Study from a Chinese Center. Gastroenterol Res Pract. 2016;2016:9381759.

80. Ando T, Tsuyuguchi T, Okugawa T, et al. Risk factors for recurrent bile duct stones after endoscopic papillotomy. Gut. 2003:52:116-21.

81. Toouli J. Sphincter of Oddi: Function, dysfunction, and its management. J Gastroenterol Hepatol. 2009 Oct;24 Suppl 3:S57-62.

82. Tran Z V. WA, Glass G V., Mood D P. The effects of exercise on blood lipids and lipoproteins: a meta-analysis of studies. Med Sci Sports Exerc. 1983;15:393-402 
83. Tsai T-J, Lai K-H, Lin C-K, Chan H-H, Wang EM, Tsai W-L, et al. Role of endoscopic papillary balloon dilation in patients with recurrent bile duct stones after endoscopic sphincterotomy. Journal of the Chinese Medical Association. 2015;78(1):56-61.

84. Tseng M EJ, Sandler RS. Dietary intake and gallbladder disease: a review. Public Health Nutrition. 1999;2.

85. Tsujino T, Kawabe T, Komatsu $\mathrm{Y}$, Yoshida $\mathrm{H}$, Isayama $\mathrm{H}$, Sasaki $\mathrm{T}$, et al Endoscopic papillary balloon dilation for bile duct stone: immediate and long-term outcomes in 1000 patients. Clin Gastroenterol Hepatol. 2007 Jan;5(1):130-7.

86. Ueda T, Kikuyama M, Kodama Y, Kurokami T. Short-Term Biliary Stent Placement Contributing Common Bile Duct Stone Disappearance with Preservation of Duodenal Papilla Function. Gastroenterol Res Pract. 2016;2016:6153893.

87. Ueno N, Ozawa Y, Aizawa T. Prognostic Factors for Recurrence of Bile Duct Stones after Endoscopic Treatment by Sphincter Dilation. Gastrointestinal endoscopy. 2003;58(3):336-40.

88. Vítek L, Carey MC. New pathophysiological concepts underlying pathogenesis of pigment gallstones. Clinics and Research in Hepatology and Gastroenterology. 2012;36(2):122-9.

89. von Schonfels W BS, Wolk $\mathrm{M}$, et al. Recurrence of gallstones after cholecystectomy is associated with ABCG5/8 genotype. J Gastroenterol. 2013;48:391-6.

90. W. TB. Pigment gallstone disease. Gastroenterol Clin North Am. 1991;20:111-26.

91. Wang HH, Portincasa P, de Bari O, Liu KJ, Garruti G, Neuschwander-Tetri BA, et al. Prevention of cholesterol gallstones by inhibiting hepatic biosynthesis and intestinal absorption of cholesterol. European Journal of Clinical Investigation. 2013;43(4):413-26

92. Williams E, Beckingham I, El Sayed G, Gurusamy K, Sturgess R, Webster G, et al. Updated guideline on the management of common bile duct stones (CBDS). Gut. 2017;66(5):765-82.

93. Yamamoto Ryuichi. TS, Kanno Keishi., Igarashi Yoshinori., Inui Kazuo., Ohara Hirotaka., Tsuyuguchi Toshio., Ryozawa Shomei. Ursodeoxycholic acid after bile duct stone removal and risk factors for recurrence: a randomized trial. J Hepatobiliary Pancreat Sci. 2016;23(2):132-6.

94. Yang J, Peng JY, Pang EJ, Chen W. Efficacy of endoscopic nasobiliary drainage for the prevention of post-endoscopic retrograde cholangiopancreatography pancreatitis and cholangitis after repeated clearance of common bile duct stones: experience from a Chinese center. Dig Endosc. 2013 Jul;25(4):453-8.

95. Yasuda I, Fujita N, Maguchi H, Hasebe O, Igarashi Y, Murakami A, et al. Long-term outcomes after endoscopic sphincterotomy versus endoscopic papillary balloon dilation for bile duct stones. Gastrointestinal endoscopy. 2010;72(6):1185-91.

96. Yoo ES, Yoo BM, Kim JH, Hwang JC, Yang MJ, Lee KM, et al. Evaluation of risk factors for recurrent primary common bile duct stone in patients with cholecystectomy. Scandinavian journal of gastroenterology. 2018;53(4):466-70.

97. Zhang $\mathrm{R}$, Luo $\mathrm{H}$, Pan $\mathrm{Y}$, Zhao $\mathrm{L}$, Dong J, Liu $\mathrm{Z}$, et al. Rate of duodenal-biliary reflux increases in patients with recurrent common bile duct stones: evidence from barium meal examination. Gastrointestinal endoscopy. 2015;82(4):660-5.

98. Zhou X-D, Chen Q-F, Zhang Y-Y, Yu M-J, Zhong C, Liu Z-J, et al. Outcomes of endoscopic sphincterotomy vs open choledochotomy for common bile duct stones. World Journal of Gastroenterology. 2019;25(4):485-97. 